\title{
Recurrent thrombosis and anticardiolipin antibodies associated with adenocarcinoma of the lung
}

\author{
Mohammed N. Shaukat and Peter Hughes
}

University Department of Medicine, Northern General Hospital, Sheffield S5 7AU, UK.

\begin{abstract}
Summary: A case of adenocarcinoma of the lung, in which high titre anticardiolipin antibodies were associated with recurrent venous thromboses resistant to all forms of therapy, is described. It is suggested that such an autoimmune response may be a contributory factor in the para-neoplastic development of vascular thromboses.
\end{abstract}

\section{Introduction}

Antiphospholipid antibodies, detected either by their ability to react with the prothrombin activator complex in the lupus anticoagulant test ${ }^{1}$ or to cross-react with cardiolipin in ELISA ${ }^{2}$ or radioimmunoassays, ${ }^{3}$ are known to predispose to venous and arterial thrombosis ${ }^{4}$ and recurrent fetal loss ${ }^{5}$ and to be associated with thrombocytopenia ${ }^{6}$ and haemolytic anaemia. ${ }^{4}$ Although originally described in patients with systemic lupus erythematosus, they are known now to occur not only in other connective tissue diseases ${ }^{7,8}$ but also in patients with purely thrombotic manifestations and/or fetal loss, the so-called antiphospholipid syndrome. ${ }^{9}$ They have also been described as a complication of a range of bacterial and viral infections ${ }^{10}$ and may occur as a side effect of certain drugs. ${ }^{11}$

There have also been sporadic reports of their association with malignancy, with the growing number of these reports suggesting that the association may not be fortuitous. The present case report of recurrent severe deep venous thrombosis in a patient with adenocarcinoma of the lung and high titre anticardiolipin antibodies adds further weight to the possibility that these antibodies may be a hitherto unrecognized factor in the development of the thrombotic problems which frequently complicate malignant disease.

\section{Case report}

A 51 year old man was admitted with a 3-day history of pain and swelling of the left calf and a one day history of left sided pleuritic chest pain. A venogram confirmed the diagnosis of a deep venous thrombosis affecting the left leg while a

Correspondence: P. Hughes, M.D., F.R.C.P.

Accepted: 6 September 1989 chest X-ray showed changes at the left base consistent with pulmonary infarction. His previous health had been good but he had smoked 25 cigarettes a day for several years. He was treated initially with intravenous heparin and then warfarin, on which he was eventually discharged.

Three weeks later he had to be readmitted with right sided pleuritic chest pain, marked breathlessness and signs now of a massive deep venous thrombosis affecting the right leg. Chest $\mathrm{X}$-ray now showed bilateral basal lung shadowing consistent, once more, with pulmonary infarction. The International Normalised Ratio was therapeutic at 2.54 but tests for anticardiolipin antibodies (see later) were now positive. He was again treated with intravenous heparin for 10 days and commenced on prednisolone and azathioprine, on which he was discharged together with continuing warfarin treatment.

He had to be readmitted on 2 further occasions with recurrent deep venous thromboses of both the left and right legs, in the course of which further chest X-rays now revealed the development of a mass in the right upper lobe. Although bronchoscopy was unhelpful, a computed tomographic scan confirmed the presence of the mass together with enlarged mediastinal lymph nodes and biopsy of one of these nodes at mediastinoscopy revealed the presence of an infiltrating adenocarcinoma. He was treated with palliative deep X-ray therapy and maintained on continuing treatment with aspirin, warfarin, subcutaneous heparin injections, prednisolone and azathioprine. Despite this combined therapeutic approach, he redeveloped further massive venous thrombosis of the left leg (the fifth such event in total and the third involving the left leg) which now was complicated by the development of extensive venous gangrene which progressed, despite continuing full combined anticoagulation with intravenous heparin, aspirin and warfarin and led 
to his death some 7 months after the initial presentation.

\section{Additional investigations}

Haemoglobin $10.5 \mathrm{~g} / \mathrm{dl}$, white cell count $12.66 \times$ $10^{9} / \mathrm{l}$, platelets $632 \times 10^{9} / 1$, erythrocyte sedimentation rate $99-128 \mathrm{~mm} / \mathrm{h}$, fibrinogen $8.6 \mathrm{~g} / \mathrm{l}$ (NR $1.8-4.5 \mathrm{~g} / \mathrm{l})$, kaolin cephalin clotting time 54 seconds (NR 40-50 seconds), lupus anticoagulant, heat stable inhibitor - patient 59 seconds, control 49 seconds, dilute Russell viper venom time platelet substitute, patient 59 seconds, control 36 seconds - washed platelets, patient 43 seconds, control 29 seconds, serial tests for anticardiolipin antibodies - IgG 20.6 units, 12.8 units, 9.3 units and 6.3 units (NR $<8.0$ units) $-\operatorname{IgM}<1$ unit, $<1$ unit, 1.7 units and 50.4 units $(\mathrm{NR}<5.0$ units), antithrombin 3 - chromogenic $111 \%$ (NR 80-120\%) - immunodiffusion $0.34 \mathrm{~g} / \mathrm{l}$ (NR $0.15-0.45 \mathrm{~g} / \mathrm{l})$, DNA antibodies, antinuclear antibodies and precipitating antibodies to nuclear and cytoplasmic antigens all negative, immunoglobulins, G 19.7 g/l, A 5.4 g/l, M 0.6 g/l.

\section{Discussion}

The association of vascular thrombosis with malignant disease, the so-called Trousseau syndrome, ${ }^{12}$ is well recognized but the mechanisms responsible for the recurrent thrombotic tendency, which characteristically may be resistant to full anticoagulation, as in the present case, have not been clearly defined. It has been suggested that some tumours are capable of releasing thromboplastin-like substances which act on pro-coagulant systems in the circulation to produce a hypercoagulable state. ${ }^{13}$ Clinical models in which intravenous injection of various tissue thromboplastins can induce a coagulopathy with both thrombotic and haemorrhagic manifestations with disseminated intravascular coagulation certainly do mimic the features found in some patients with Trousseau's syndrome. ${ }^{14}$

The present case, however, showed no evidence of disseminated intravascular coagulation with, in fact, 'acute phase' increases of both fibrinogen and platelets that almost certainly played a predisposing and synergistic role in the development of the recurrent venous thromboses. The finding of high titre anticardiolipin/antiphospholipid antibodies as an additional factor in our patient's recurrent and severe thrombotic tendency is, therefore, particularly interesting. These antibodies, especially when present in high titre and of IgG isotype, are known to have a predictive value for thrombotic events in patients with autoimmune disorders. ${ }^{4}$ However, this predisposition to thrombosis has also been recognized with antibodies of both $\operatorname{IgA}$ and IgM isotypes ${ }^{15}$ which is particularly relevant to the present case in which continuing thrombotic events were associated with a change in the isotype of the anticardiolipin antibody from $\operatorname{IgG}$ to IgM. Anticardiolipin/antiphospholipid antibodies, which are thought to predispose to thrombosis by interfering with prostacyclin release from vascular endothelium $^{16}$ and by interacting with phospholipid antigens in platelets, ${ }^{17}$ have only been reported sporadically in patients with malignant disease. Previous reports, which have frequently relied on the lupus anticoagulant test to detect these antibodies indirectly, have described their presence in patients with leukaemia, ${ }^{18}$ lymphoma, multiple myeloma, ${ }^{19}$ thymoma ${ }^{20}$ maxillary carcinoma ${ }^{21}$ and, as in the present report, bronchial carcinoma. ${ }^{22}$ The growing number of such reports suggests that the association may not be entirely fortuitous.

Autoantibodies arising from what is an immune response directed primarily against tumour antigens have been described as producing autoimmune haemolysis, the Eaton-Lambert (myasthenic) syndrome $\mathrm{e}^{23}$ and paraneoplastic visual dysfunction ${ }^{24}$ and cerebellar degeneration ${ }^{25}$ in patients with malignancy. Polymyositis and the peripheral neuropathy that is frequently found in many patients with carcinoma are similarly likely to have an immunological basis. The finding of autoantibodies capable of reacting with phospholipids, which are widely distributed in cell membranes, should therefore not be unexpected. Now that sensitive and reliable assays are available for the detection of anticardiolipin/antiphospholipid antibodies, screening of patients with malignant disease may well reveal a hitherto unsuspected incidence of these potentially pathogenic autoantibodies, especially in those patients with thrombotic manifestations.

\section{Acknowledgements}

We are grateful to the Departments of Haematology, Northern General Hospital and Royal Hallamshire Hospital, Sheffield, for the estimations of lupus anticoagulant and anticardiolipin antibodies, respectively. 


\section{References}

1. Shapiro, S.S. \& Thiagarajan, P. Lupus anticoagulant. Prog Hemost Thromb 1982, 6: 263-285.

2. Loizou, S., McCrea, J.D., Rudge, A.C., Reynolds, R., Boyle, C.C \& Harris, E.N. Measurement of anticardiolipin antibodies by an enzyme-linked immunosorbent assay (ELISA): standardisation and quantitation of results. Clin Exp Immunol 1985, 62: 738-745.

3. Harris, E.N., Gharavi, A.E., Boey, M.L. et al. Anticardiolipin antibodies: detection by radioimmunoassay and association with thrombosis in systemic lupus erythematosus. Lancet 1983, ii: $1211-1214$.

4. Harris, E.N., Chan, J.K.H., Asherson, R.A., Aber, V.R., Gharavi, A.E. \& Hughes, G.R.V. Thrombosis, recurrent fetal loss and thrombocytopenia: predictive value of the anticardiolipin antibody test. Arch Intern Med 1986, 146: 2153-2156.

5. Lockshin, M.D., Druzin, M.L., Goei, S. et al. Antibody to cardiolipin as a predictor of fetal distress or death in pregnant patients with systemic lupus erythematosus. $N$ Engl J Med 1985, 313: 152-156.

6. Harris, E.N., Gharavi, A.E. \& Hedge, U. Anticardiolipin antibodies in autoimmune thrombocytopenic purpura. $\mathrm{Br} \mathrm{J}$ Haematol 1984, 59: 231-234.

7. Malia, R.G., Greaves, M., Rowlands, L.M. et al. Anticardiolipin antibodies in systemic sclerosis: immunological and clinical associations. Clin Exp Immunol 1988, 73: 456-460.

8. Keane, A., Woods, R., Dowding, V., Roden, D. \& Barry, C. Anticardiolipin antibodies in rheumatoid arthritis. $\mathrm{Br} J$ Rheumatol 1987, 26: 346-350.

9. Hughes, G.R.V. Thrombosis, abortion, cerebral disease and the lupus anticoagulant. $\mathrm{Br}$ Med J 1983, 287: 1088-1089.

10. Harris, E.N., Gharavi, A.E. \& Hughes, G.R.V. Antiphospholipid antibodies. Clin Rheum Dis 1985, 11: 591-609.

11. Canoso, R.T. \& Sise, H.S. Chlorpromazine-induced lupus anticoagulant and associated immunologic abnormalities. Am J Haematol 1982, 13: 121-129.

12. Bell, W.R., Starksen, N.F., Tong, S. \& Porterfield, J.K. Trousseau's syndrome: devastating coagulopathy in the absence of heparin. Am J Med 1985, 79: 423-430.

13. Rickles, F.R. \& Edwards, R.L. Activation of blood coagulation in cancer: Trousseau's syndrome revisited. Blood 1983, 62: $14-31$.
14. Hartmann, R.C., Conley, C.L. \& Krevans, J.R. The effect of intravenous infusion of thromboplastin on heparin tolerance'. J Clin Invest 1951, 30: 948-956.

15. Gharavi, A.E., Harris, E.N., Asherson, R.A. \& Hughes, G.R.V. Anticardiolipin antibodies: isotype distribution and phospholipid specificity. Ann Rheum Dis 1987, 46: 1-6.

16. Carreras, L.O. \& Vermylen, J.G. 'Lupus' anticoagulant and thrombosis - possible role of inhibition of prostacyclin formation. Thromb Haemost 1982, 48: 38-40.

17. Cortellazio, S., Galli, M., Viero, P. \& Babui, T. Interaction between lupus anticoagulant and platelets. Thromb Haemost 1987, 58: Abstracts, 391.

18. Duncombe, A.S., Dalton, R.G. \& Savidge, G.F. Lupus type coagulation inhibitor in hairy cell leukaemia and resolution with splenectomy. Br J Haematol 1987, 65: 120-121.

19. Dührsen, U., Paar, D., Kölbel, C. et al. Lupus anticoagulan associated syndrome in benign and malignant systemic disease - analysis of ten observations. Klin Wochenschr 1987 68: $852-859$.

20. Levine, S.R., Diaczok, I.M., Deegan, M.J. et al. Recurrent stroke associated with thymoma and anticardiolipin antibodies. Arch Neurol 1987, 44: 678-679.

21. Tu, H., Davis, R.B. \& Davis, L.F. Lupus anticoagulant in a patient undergoing oral surgery. J Oral Maxillofac Surg 1984, 42: 53-55.

22. Kozlowski, C.L., Johnson, M.J., Gorst, D.W. \& Willey, R.F Lung cancer, immune thrombocytopenia and the lupus inhibitor. Postgrad Med J 1987, 63: 793-795.

23. Lang, B., Newsom-Davis, J., Wray, D., Vincent, A. \& Murray, N. Autoimmune aetiology for myasthenic (EatonLambert) syndrome. Lancet 1981, ii: 224-226.

24. Grunwald, G.B., Klein, R., Simmonds, M.A. \& Kornguth S.E. Autoimmune lasis for visual paraneoplastic syndrome in patients with small-cell lung carcinoma. Lancet 1985, i: $658-661$.

25. Greenlee, J.E. \& Brashear, H.R. Antibodies to cerebellar Purkinje cells in patients with paraneoplastic cerebellar degeneration and ovarian carcinoma. Ann Neurol 1983, 14: $609-613$ 